\title{
REVIEW
}

\section{Treatment of Acne Keloidalis Nuchae: A Systematic Review of the Literature}

Eric L. Maranda • Brian J. Simmons • Austin H. Nguyen • Victoria M. Lim •

Jonette E. Keri

Received: June 16, 2016 / Published online: July 18, 2016

(C) The Author(s) 2016. This article is published with open access at Springerlink.com

\section{ABSTRACT}

Acne keloidalis nuchae (AKN) is a chronic inflammatory condition that leads to fibrotic plaques, papules and alopecia on the occiput and/or nape of the neck. Traditional medical management focuses on prevention, utilization of oral and topical antibiotics, and intralesional steroids in order to decrease inflammation and secondary infections. Unfortunately, therapy may require months of treatment to achieve incomplete results and recurrences are common. Surgical approach to treatment of lesions is invasive, may require general anesthesia and requires more time to recover. Light and laser therapies offer an alternative treatment for AKN. The present study systematically reviews the currently available

Enhanced content To view enhanced content for this article go to http://www.medengine.com/Redeem/ E1E4F060549DE1A0.

E. L. Maranda · B. J. Simmons · J. E. Keri Department of Dermatology and Cutaneous Surgery, University of Miami Miller School of Medicine, Miami, FL, USA

A. H. Nguyen · V. M. Lim ( $₫)$ Creighton University School of Medicine, Omaha, NE, USA

e-mail: victoriamlim@gmail.com literature on the treatment of AKN. While all modalities are discussed, light and laser therapy is emphasized due to its relatively unknown role in clinical management of $\mathrm{AKN}$. The most studied modalities in the literature were the 1064-nm neodymium-doped yttrium aluminum garnet laser, 810-nm diode laser, and $\mathrm{CO}_{2}$ laser, which allow for $82-95 \%$ improvement in 1-5 sessions. Moreover, side effects were minimal with transient erythema and mild burning being the most common. Overall, further larger-scale randomized head to head control trials are needed to determine optimal treatments.

Keywords: Acne keloidalis nuchae; Hair disorders; Lasers; Systematic review; Therapy; Treatment

\section{INTRODUCTION}

Acne keloidalis nuchae (AKN) is a chronic inflammatory condition that leads to scarring of the hair follicles, development of keloid-like papules and plaques, and scarring alopecia on the nape of the neck and occipital scalp. Studies 
report the incidence of $\mathrm{AKN}$ being between $0.45 \%$ and $9 \%$, and occurring mostly in darkerskinned races with curly or kinky hair [1-5]. While this condition most commonly occurs in blacks, AKN can also be seen in Caucasians [29]. Moreover, the condition has a predilection for men, occurring 20 times more frequently than in women [6], and starts after adolescence. The natural course of disease starts with the early formation of inflamed papules with marked erythema. Secondary infection can lead to pustules and abscess formation in some cases. Over time, continued inflammation leads to pronounced fibrosis and keloid formation with coalescence of the papules into large plaques and nodules. Later stages of presentation include chronic scarring and/or scarring alopecia without active inflammation.

While the exact underlying pathogenesis of AKN is not known, the two predominant theories suggest skin injury and the existence of aberrant immune reactions as the underlying causes. Skin injuries from irritation, occlusion, trauma, friction and hair cutting practices have all been implicated as risk factors for the development of AKN [7-10]. The characteristic curvature of afro-textured hair has also been implicated in inciting $\mathrm{AKN}$, but no clinical or pathologic evidence exists to substantiate this [11]. Furthermore, some have proposed that $\mathrm{AKN}$ is due to an immune reaction that leads to the cicatricial alopecia. Upon histological examination, a mixed, neutrophilic and lymphocytic infiltration has been observed [36]. In this theory, intrafollicular antigens attract inflammatory cells to the follicle, resulting in damage to the sebaceous gland and follicular wall. This in turn leads to rupture of the follicle and release of antigens into the hair follicle that precipitates the inflammatory process and epithelial destruction leading to fibrosis [12].
Traditional management of the disease focuses on preventing disease progression, including avoidance of mechanical irritation from clothing and use of antimicrobial cleansers to prevent secondary infection [13]. Treatment usually involves use of topical, intralesional or systemic steroids in combination with retinoids and/or antibiotics to decrease inflammation $[14,15]$. When the disease progresses from early to late stage, surgical excision and skin grafting may be performed, which require long periods of healing. Recent advances in light and laser therapies offer an alternative treatment option for AKN. However, the potential of these modalities in the treatment for $\mathrm{AKN}$ has not been comprehensively reviewed. This review explores medical, surgical and light therapies for $\mathrm{AKN}$ and discusses the clinical implications.

\section{METHODS}

A literature review of the National Library of Medicine database, PubMed, was performed on July 6, 2015 (Fig. 1). The following search terms were used individually: "Acne Keloidalis Nuchae", "Folliculitis Keloidalis Nuchae", "Acne Keloidalis" and "Folliculitis Keloidalis". Search results were cross-checked with the Scopus database using the same search terms. Initial searching returned 558 articles. Only articles written in English were included for further review. The titles and abstracts of the articles were independently reviewed by two authors for relevance to the treatment of AKN. Articles were included if they were original studies and contained suitable background information, clinical presentation, and treatment information for AKN. A total of 22 studies were included, containing 85 total patients treated with different modalities. The 


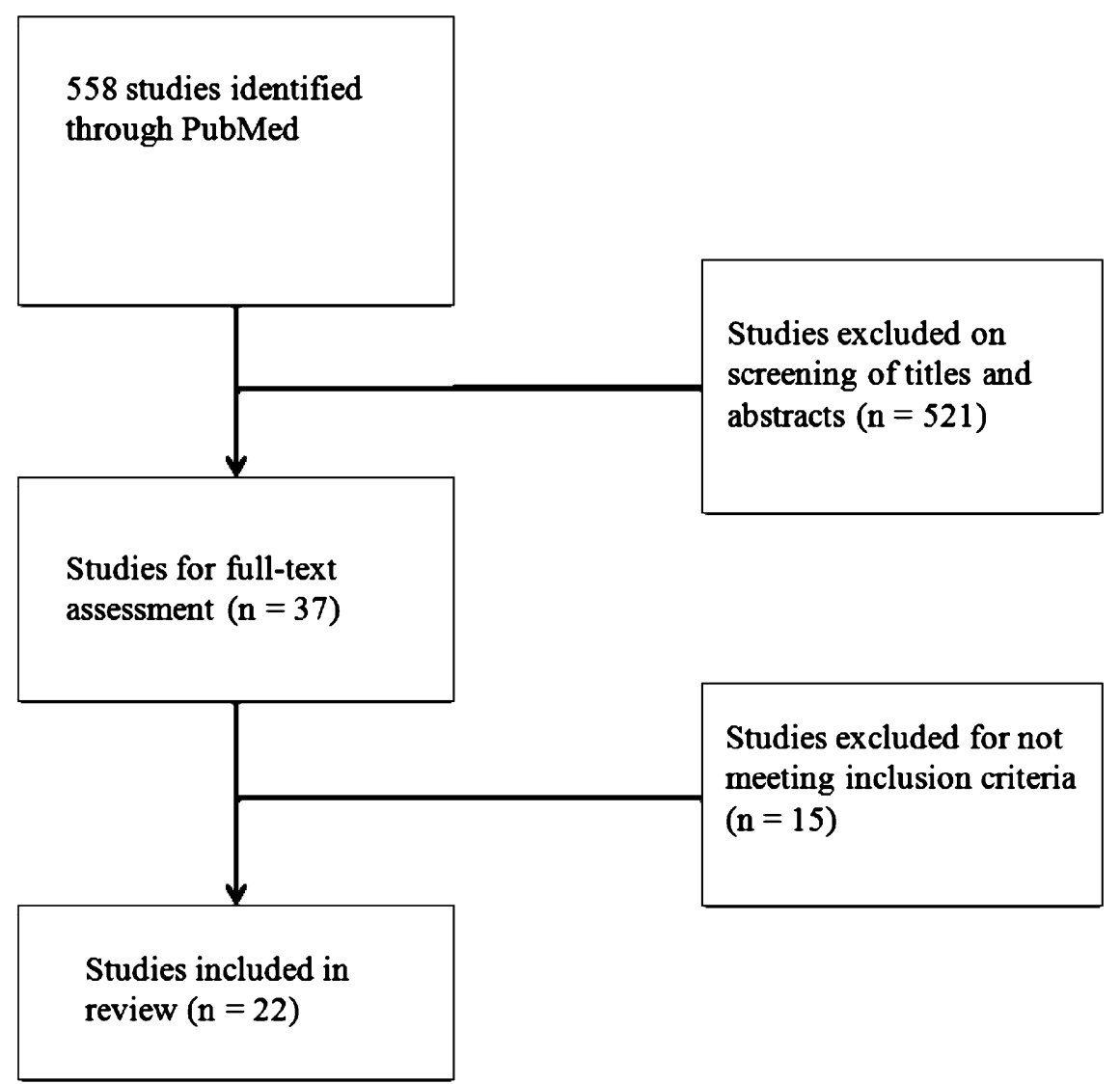

Fig. 1 Systematic search of PubMed returned 558 total studies. After review of titles, abstracts, and full-text, 22 studies were included in this review

majority of studies were case reports/case series. This article is based on previously conducted studies and does not involve any new studies of human or animal subjects performed by any of the authors.

\section{RESULTS}

\section{Conventional Modalities}

A total of 15 studies were found utilizing medical and surgical treatments for AKN (see Tables 1, 2). Medical management included the use of topical or oral antibiotics, corticosteroids, retinoids, topical fusidic acid and topical urea. Medical management showed varying degrees of improvement, with complete resolution in one case. Overall, surgical approaches to treating AKN resulted in a drastic improvement of the condition, though there was some recurrence of disease and the cosmetic results were variable. Additionally, there was one report on radiotherapy and dermabrasion.

\section{Medical Treatment}

The earliest case of medical management of AKN was reported by Dinehart et al. [16] who treated two females with intralesional triamcinolone and tetracycline (oral), respectively. There was marked improvement in both patients. The patient receiving 


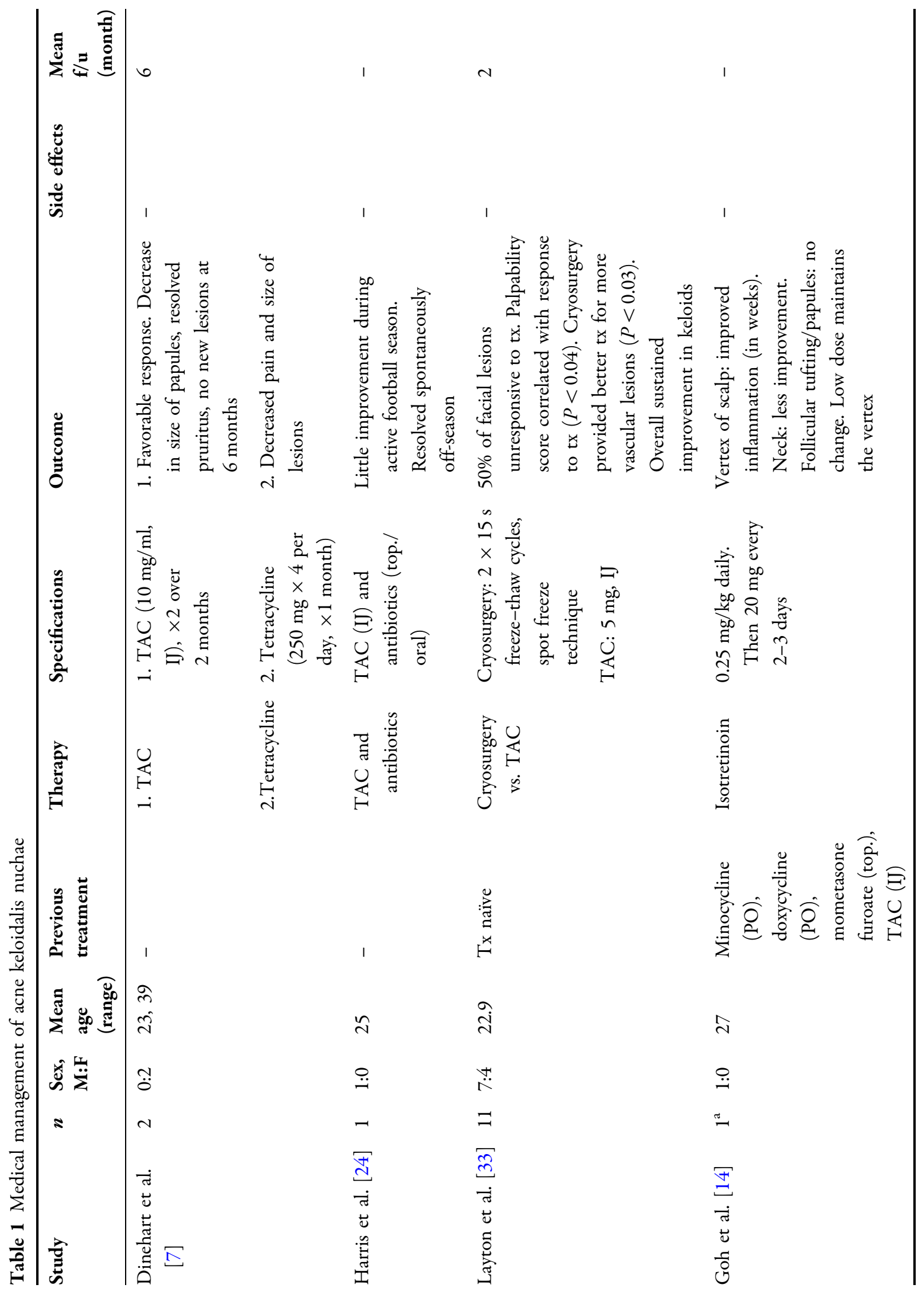




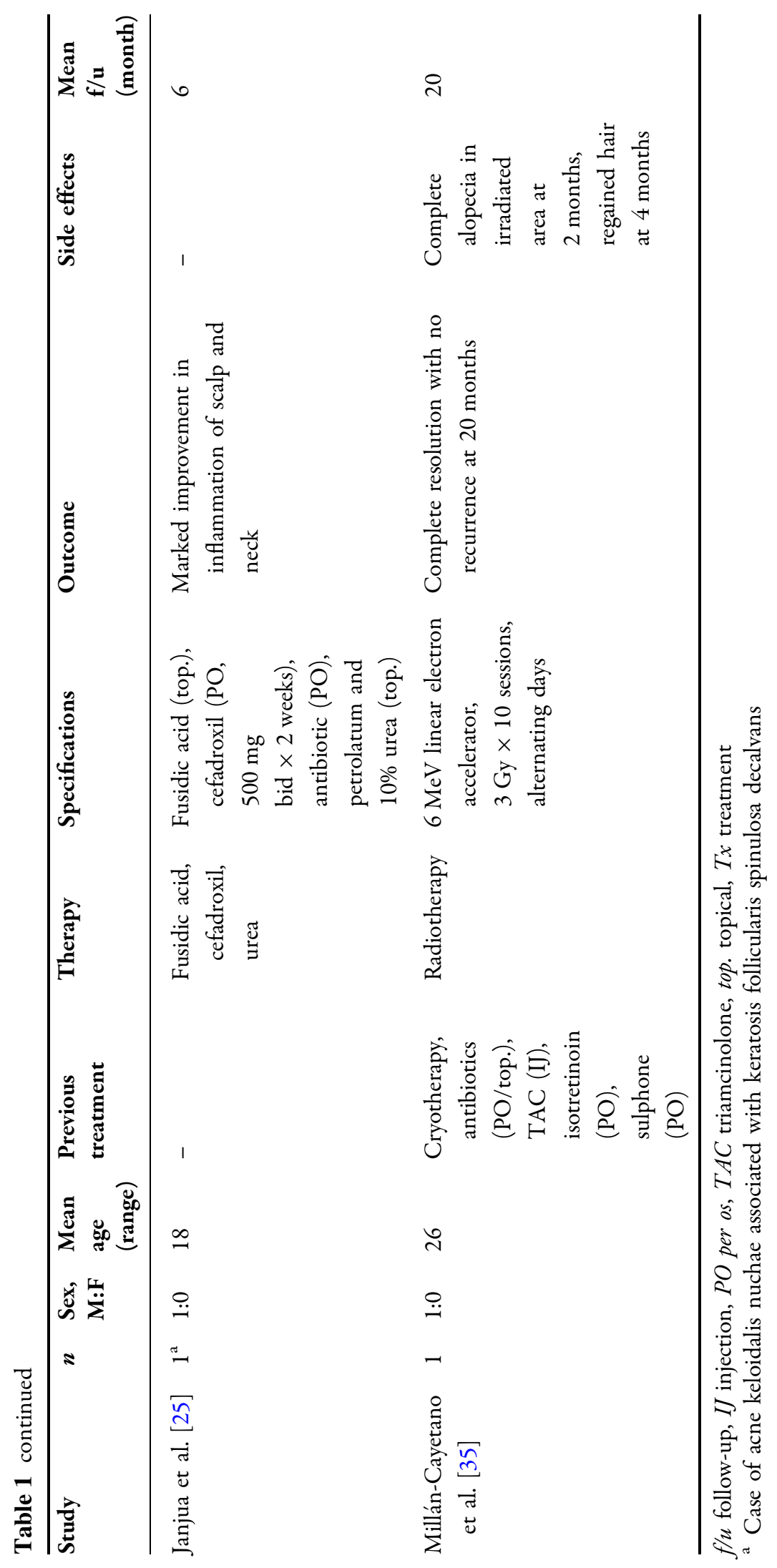




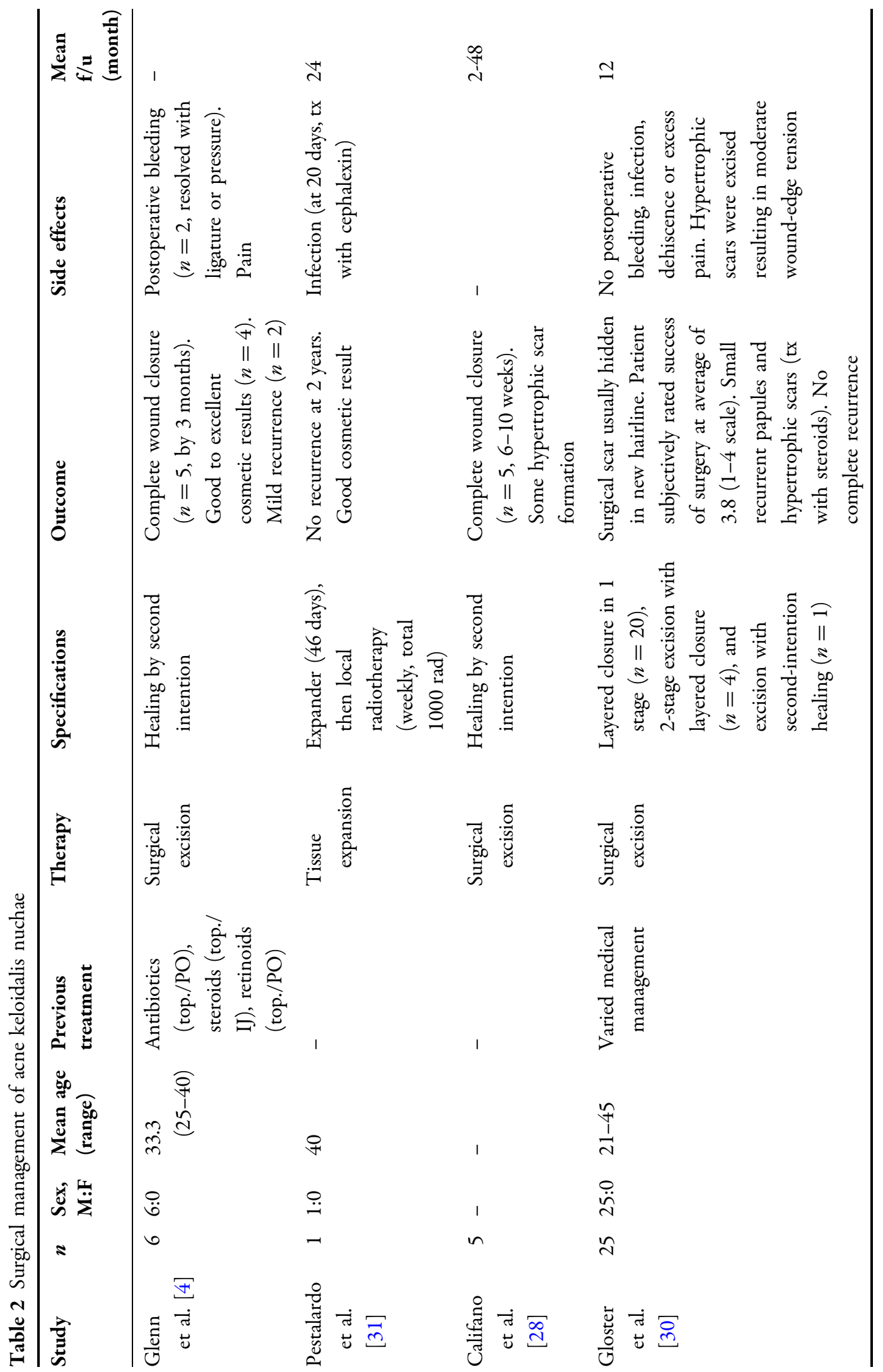




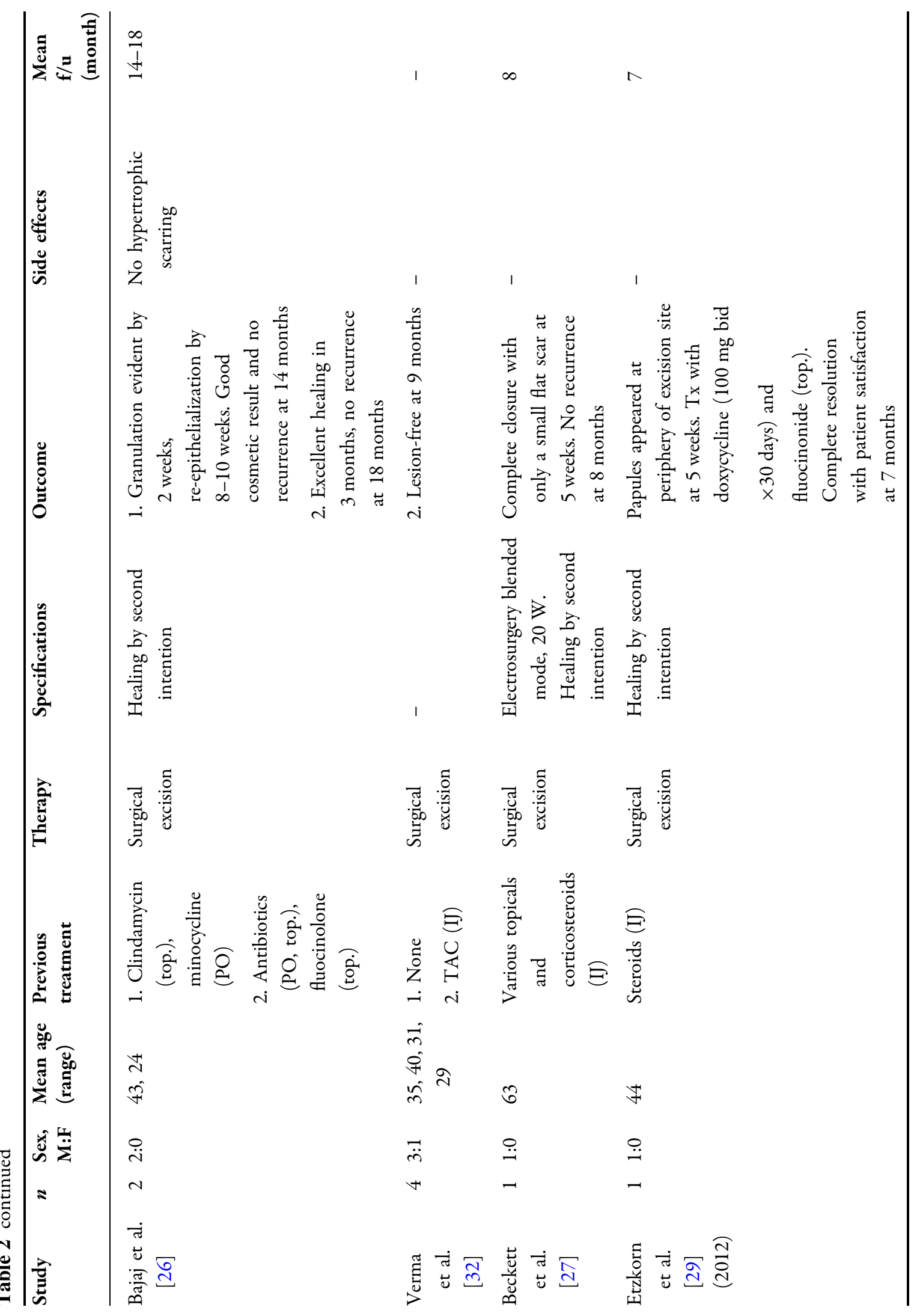




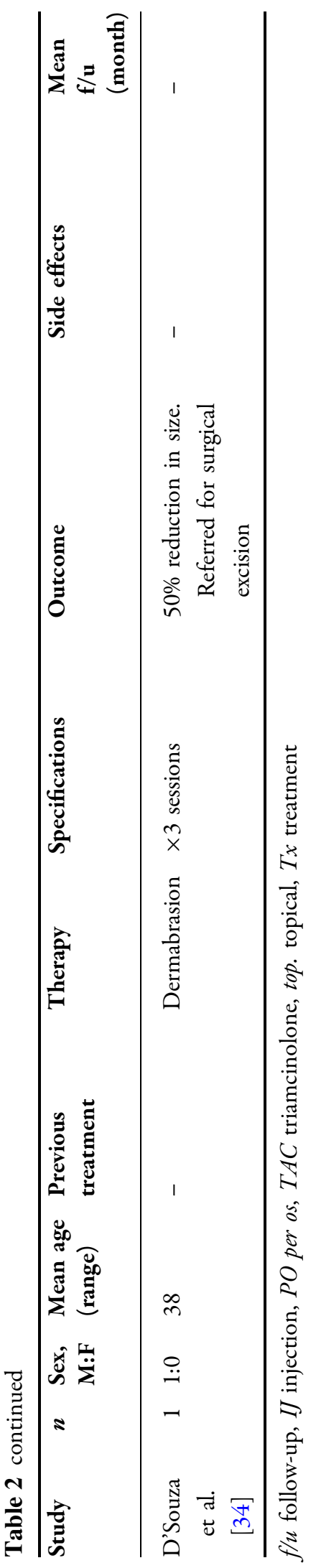

triamcinolone had no new lesions at 6 months, though many small papules remained; the patient receiving tetracycline had dramatic improvement, including a decrease in pain, size and purulence of the lesions. Conversely, Harris et al. [17] reported a case of $A K N$ in a male professional football player. Triamcinolone and antibiotics were administered with little improvement seen until the patient's offseason, at which time the condition spontaneously resolved. Medical management has also been a suitable therapeutic approach for AKN associated with keratosis follicularis spinulosa decalvans [14, 18]. Two cases have been reported, both involving young men (aged 18 and 27 years, respectively). Goh et al. [14] utilized oral isotretinoin (20 mg, $0.25 \mathrm{mg}$ / $\mathrm{kg}$ /day) after failed attempts with minocycline (oral), doxycycline (oral), mometasone furoate (topical) and triamcinolone acetate (intralesional injection). Within weeks, dramatic improvement was seen in the lesions on the vertex of the patient's scalp. Inflammation on the neck responded less dramatically, while the patient's follicular tufting/follicular hyperkeratotic papules exhibited no change. Maintenance on low dose isotretinoin (20 mg every 2-3 days) kept the patients vertex inflammation under control, seen at 1-year follow-up. Janjua et al. [18] used combination topical fusidic acid and oral cefadroxil (500 mg twice daily for 2 weeks) to treat a patient. Antibacterial therapy was repeated as necessary. There was marked improvement in the lesions of the scalp and nuchal area at 6 months, though some hypertrophic scarring and tufts remained. Overall, medical management seemed to improve the condition, though complete resolution was not seen. Thus, the modality may be reserved for mild cases of AKN. 


\section{Surgical Treatment}

Surgical excision was described in eight studies $[4,19-25]$. In one report, six males with AKN refractory to numerous medications, both topical and systemic, underwent surgical excision of the involved areas to muscle fascia or deep subcutaneous tissue [4]. Healing by second intention was allowed, which resulted in an average closure time of 6-8 weeks. Good cosmetic results were achieved in four patients (those receiving horizontal elliptical excision including the posterior hairline), while recurrence occurred in two patients. Another study reported surgical excision and healing by second intention performed on five patients [21]. Although scarring was significant, the cosmetic results were acceptable in all patients. At 2 months to 4 years follow-up, contractures did not limit function nor did disease recur. In two similar studies by Bajaj et al. [19] and Etzkorn et al. [22], a total of three cases of AKN were surgically excised with healing by second intention. Excellent cosmetic results and no recurrences were seen (follow-up at 7, 14 and 18 months, respectively).

Electrosurgery is another treatment option for AKN. This modality allows for excision of the lesion with simultaneous coagulation of small vessels similar to laser excision with $\mathrm{CO}_{2}$. In one case utilizing electrosurgery, healing by second intention resulted in complete closure at 5 weeks with good wound contracture and a small flat scar [20]. No recurrence was observed at 8 months postoperative. In the largest study to date, Gloster et al. [23] performed surgical excision in 25 patients with AKN. Twenty patients underwent excision with layered closure in 1 stage, 4 underwent 2-stage excision with layered closure and one underwent excision with second-intention healing. Treated areas were subjectively scored from poor (1) to excellent (4) by both the patient and physician. At 1-year follow-up, the results were scored with an average overall score of 3.8. Five patients, however, developed hypertrophic scarring and 15 patients had mild recurrences of tiny pustules and papules during the first 4 months that were subsequently treated with topical and intralesional steroids.

An alternative surgical approach was taken in a case of $\mathrm{AKN}$ in a 40-year-old male using a semilunar 400-ml tissue expander [24]. Postoperative infiltrations were performed at 14 days and each week thereafter, expanding the tissue by $380 \mathrm{ml}$. At the $46 \mathrm{th}$ post-operative day, the expander was removed and the affected area was closed. Local radiotherapy was administered weekly until $1000 \mathrm{rad}$ was reached. An excellent cosmetic result was achieved, with no recurrence of $\mathrm{AKN}$ and no signs of the "stretch-back" phenomenon at 2-year follow-up. The case was complicated by infection at 20 days post-operation that was successfully treated with cephalexin.

A variety of combined treatments have also been reported for the treatment of AKN. Layton et al. [26] compared intralesional triamcinolone with cryosurgery using the spot freeze technique with two 15-s freeze-thaw cycles. Overall, the assigned scores of pre-therapy palpability (used as an indicator of severity) correlated with the response to treatment $(P<0.04)$ and cryosurgery provided better results for more vascular lesions $(P<0.03)$. At 8 -week follow-up, there were sustained improvements in the lesions. Dermabrasion was attempted in one case of $\mathrm{AKN}$ in a 38-year-old male [27]. After three sessions, there was approximately a 50\% reduction in lesion size. However, the patient refused additional sessions and was subsequently 
referred for surgical excision. In one particularly refractory case of AKN reported by Cayetano et al. [28], the patient was treated for 5 years with cycles of cryotherapy, topical antibiotics (clindamycin $1 \%$ solution), oral antibiotics (doxycycline $100 \mathrm{mg} /$ day), infiltrations of intralesional triamcinolone, oral isotretinoin (50 mg/day) and oral sulphone (100 mg/day). The patient also received electro-curettage and partial excision with primary closure. With continued worsening, the patient underwent radiotherapy at $3 \mathrm{~Gy}$ per session for ten sessions on alternating days (total dose of $30 \mathrm{~Gy}$ ). Complete alopecia was seen at 2 months after radiotherapy which resolved 4 months later, except in the area of the original keloid plaque. The lesion eventually flattened, leading to a small residual scar and good cosmetic results. No recurrence was seen at 20-months follow-up.

\section{Light and Laser Therapy}

Lasers utilized included the $\mathrm{CO}_{2}$ laser, 1064-nm neodymium-doped yttrium aluminum garnet (Nd:YAG) laser, 59-nm pulse dye laser (PDL), and 810-nm diode laser (Table 3). The earliest study by Kantor et al. used a $\mathrm{CO}_{2}$ laser for surgical excision for late stage treatment of $\mathrm{AKN}$ [29]. By using a $\mathrm{CO}_{2}$ laser with a focused beam, fibrotic areas in six black patients and two white patients could be removed in an outpatient-based setting with local anesthesia. Moreover, none of the patients who were treated using this modalityhad a relapse. Two patients in the study with early AKN were treated with laser evaporation using the unfocused beam setting with $130-150 \mathrm{~J} / \mathrm{cm}^{2}$ fluence with three to four passes in one session. However, relapse occurred in both cases. In another case, $\mathrm{CO}_{2}$ laser evaporation with the same fluence setting was utilized in a
Caucasian male who had developed AKN while on chronic cyclosporine treatment for a heart transplant. The patient's AKN relapsed shortly after treatment forcing the patient to undergo surgical intervention [30]. In a third case involving a Caucasian male, $\mathrm{CO}_{2}$ laser excision was coupled with a single postoperative intralesional injection of triamcinolone acetate ( $5 \mathrm{ml}$ of $25 \mathrm{mg} / \mathrm{ml}$ ) and three radiotherapy sessions of $400 \mathrm{cGY}$ [31]. The first of which was given on the same day following the procedure. The patient developed a few satellite lesions that were treated with $\mathrm{CO}_{2}$ laser excision. The patient had a full recovery and regrowth of hair in the treated region.

In a case series by Shah [32], 2 males were treated using a 810-nm diode laser who had previous treatment failures with oral antibiotics, intralesional and topical steroids. After 4 treatment sessions of $23-26 \mathrm{~J} / \mathrm{cm}^{2}$ fluence with $100 \mathrm{~ms}$ pulses, the patients had a $90 \%$ and $95 \%$ clearance, respectively, that was maintained at 6-months follow-up. Treatments were tolerated with only transient mild burning.

Dragoni et al. [33] treated a single fair-skinned 23-year-old Caucasian male using a 595-nm PDL with $6.5 \mathrm{~J} / \mathrm{cm}^{2}$ fluence and $0.5 \mathrm{~ms}$ pulse. The results, however, were transient and lesions returned in 1 month. Subsequently, a 1064-nm Nd:YAG laser with $101-120 \mathrm{~J} / \mathrm{cm}^{2}$ fluence was used for four sessions, which lead to a significant improvement in scarring that was clinically apparent. Esmat et al. [34] also used a 1064-nm Nd:YAG laser to treat patients with AKN in a pilot study using $35-45 \mathrm{~J} / \mathrm{cm}^{2}$ fluence over five sessions. Patients between the ages of 22 and 54 years old with Fitzpatrick skin types 3 and 4 were treated. Significant improvements were seen after the third treatment and in $82 \%$ of the lesions after the 5th session. Moreover, 


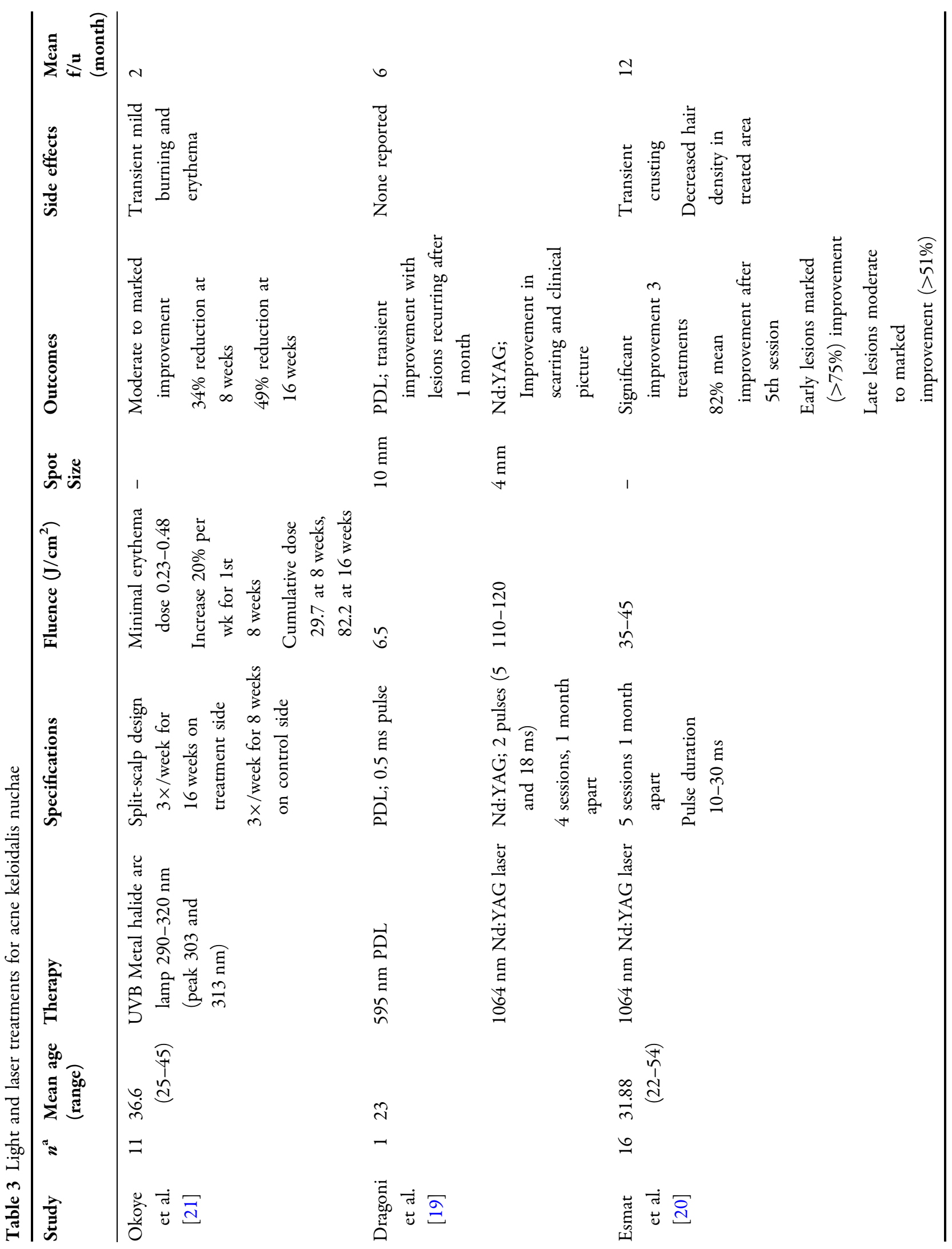




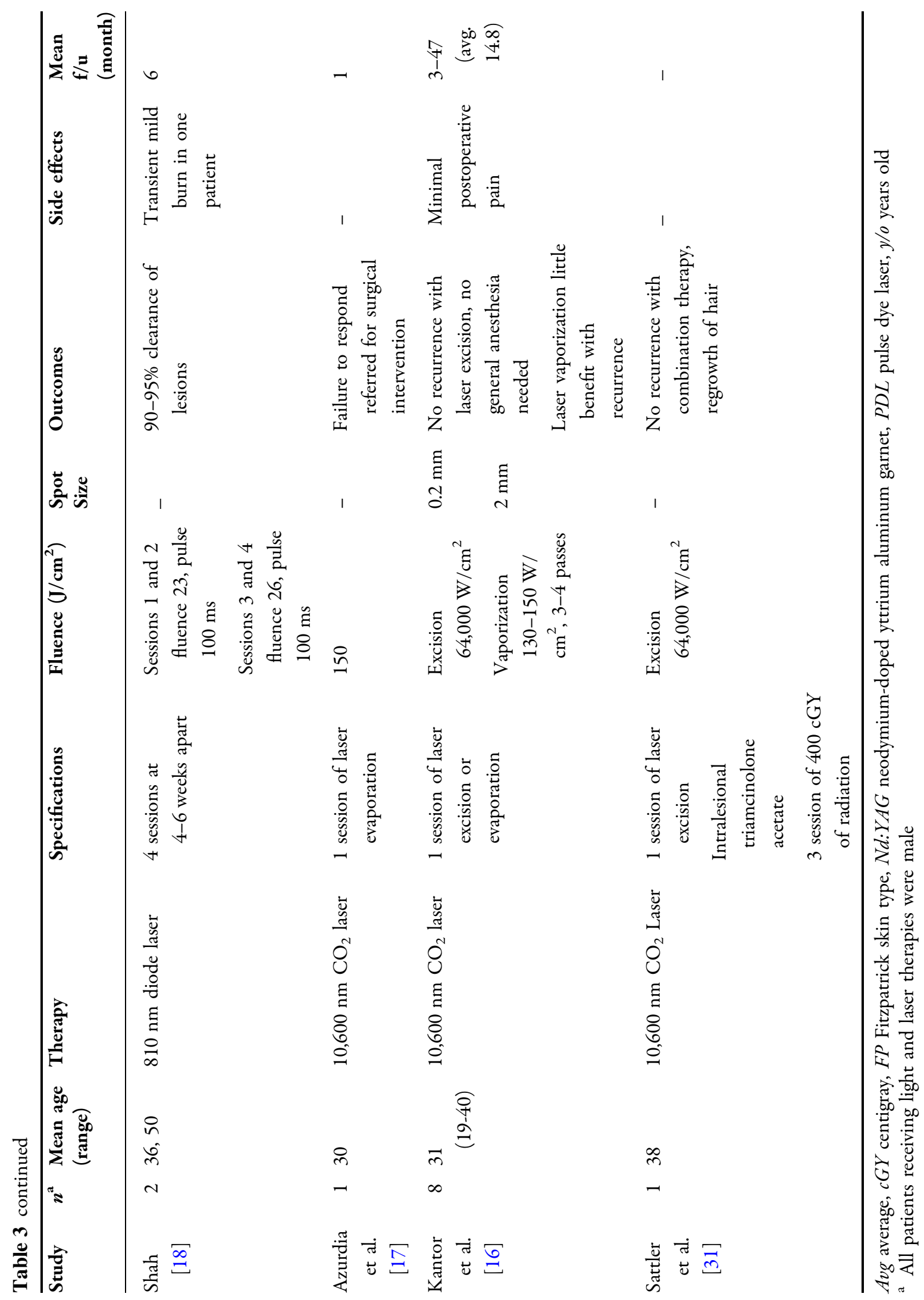


biopsies taken from the treated area showed significant reductions in the inflammatory infiltrate after the final treatment. No recurrences of lesions were noted at 1-year follow-up.

Light therapy consisted of the use of a 290to 320-nm targeted UVB (tUVB) halide arc lamp (Table 3). The most recent study by Okoye et al. [35] used tUVB light to treat 11 male patients using a split-scalp designed study. Initial UVB dosage was determined using the minimal erythema dose that ranged between 0.23 and $0.48 \mathrm{~J} / \mathrm{cm}^{2}$. Treatment dosing was increased by $20 \%$ per week until the end of 8 weeks and was maintained at the same dose for an additional 8 weeks. The control side of the scalp was treated after the 8th week according to the same protocol until the end of the study at 16 weeks. Treatments were tolerated well with only mild burning and erythema. Patients were given two to three treatments per week. A significant improvement was noted on the treated side by $34 \%$ at 8 weeks and $49 \%$ at 16 weeks. The results were maintained at 2-months follow-up. In addition to clinical improvements, an up-regulation of matrix metalloproteinases MMP1, MMP9, TGFB1 and COL1A1 were seen by histology, indicating higher rates of extracellular matrix turnover.

\section{DISCUSSION}

$\mathrm{AKN}$ is a common condition, which can lead to significant scarring, alopecia and negatively impact on quality of life. The pathogenesis of $\mathrm{AKN}$ is not completely understood, though trauma and/or immune reactions are thought to play a role. Other factors in disease progression have been suggested, such as a familial component or a cutaneous manifestation of metabolic syndrome [25, 27].
However, further investigation to elucidate the underlying pathogenesis is required.

To date, a number of treatments have been used to treat this condition, from topical antibiotics to surgical excision of fibrotic lesions. Traditional medical management can require months of daily treatment and may relapse after discontinuation of treatment [6]. Light and laser treatments can offer an alternative to medical management that is noninvasive and generally well tolerated. $\mathrm{CO}_{2}$ laser excision can be used as monotherapy in place of surgical excision of AKN lesions without the need for general anesthesia or in combination with intralesional steroids and radiotherapy. However, $\mathrm{CO}_{2}$ vaporization is not very effective in treating $\mathrm{AKN}$ because lesions recur shortly after treatment and because of the incidence of scarring in dark-skinned individuals following $\mathrm{CO}_{2}$ vaporization.

Medical management includes intralesional injection and/or topical corticosteroids, topical or oral antibiotics (particularly tetracyclines), and retinoids. Oral isotretinoin $(20 \mathrm{mg}$, $0.25 \mathrm{mg} / \mathrm{kg} /$ day) was shown to improve inflammation, but had minimal effect on follicular tufting/follicular hyperkeratotic papules. Amongst the medical modalities, patients receiving intralesional steroids had the most dramatic improvement.

Surgical excision, while extensively discussed in the literature, should be reserved for more extensive and refractory lesions. Healing by second-intention was the most common method used postoperatively. Cryosurgery provided a varied response to lesions, though may be best suited for more vascular lesions [26]. Surgical or cryosurgical treatment with secondary intention healing is the most effective treatment modality for $\mathrm{AKN}$; however, the outcomes are still not optimal. 
Of the 41 patients treated by surgical excision that were included in this review, 17 had mild recurrence. Additionally, scarring is the major concern with a surgical approach, though use of a horizontal ellipse encompassing the posterior hairline resulted in good to excellent cosmesis by allowing the surgical scar to be hidden in the newly formed hairline. Dermabrasion was reported in one case and did not achieve complete resolution. Radiotherapy was used in two cases of AKN that were refractory to extensive and aggressive treatment [28, 31]. While this modality resulted in complete resolution with no recurrence; radiotherapy should be reserved for the most severe and refractory cases, considering the side effects of such treatment.

The two most extensively studied light and laser therapies include treatment with a 1064-nm Nd:YAG laser and tUVB light. Among the light and laser modalities, the 1064-nm Nd:YAG laser and 810-nm diode laser appears to be the most effective for treating AKN. Results from these small studies are promising with therapeutic responses in the range of $82-95 \%$. While tUVB therapy was well tolerated with only mild burning and erythema, it was not as effective as the 1064-nm Nd:YAG laser, with clinical improvements in the range of $34-49 \%$.

Overall, laser and light therapies for AKN appear to work by decreasing the inflammatory response and/or destroying the hair follicle, which appears to be a nidus that prolongs the vicious cycle of inflammation and fibrosis seen with AKN. Moreover, in the case of tUVB therapy, there is a modulation in expression of matrix metalloproteinases, suggesting that extracellular matrix turnover is enhanced which may act to improve lesions [35].

\section{CONCLUSIONS}

Medical management of AKN can be used in mild cases. Surgical excision should be reserved for more extensive lesions with prominent fibrosis. However, concern for post-surgical scarring must be considered. Overall, management of $\mathrm{AKN}$ with light and laser treatments looks promising with 1064-nm Nd:YAG, 810-nm Diode, and $\mathrm{CO}_{2}$ lasers that allow for $82-95 \%$ improvement in 1-5 sessions. Moreover, side effects were minimal with transient erythema and mild burning being the most common. However, the studies are primarily based on case series and small pilot studies. Thus, larger-scaled randomized controlled trials with long-term follow-up are needed to effectively assess these treatments.

\section{ACKNOWLEDGMENTS}

No funding or sponsorship was received for this study or publication of this article. All named authors meet the International Committee of Medical Journal Editors (ICMJE) criteria for authorship for this manuscript, take responsibility for the integrity of the work as a whole, and have given final approval for the version to be published.

Disclosures. Eric L. Maranda, Brian J. Simmons, Austin H. Nguyen, Victoria M. Lim, and Jonette E. Keri have no conflicts of interest to declare.

Compliance with Ethics Guidelines. This article is based on previously conducted studies and does not involve any new studies on human or animal subjects performed by any of the authors. 
Open Access. This article is distributed under the terms of the Creative Commons Attribution-NonCommercial 4.0 International License (http://creativecommons.org/licenses/ by-nc/4.0/), which permits any noncommercial use, distribution, and reproduction in any medium, provided you give appropriate credit to the original author(s) and the source, provide a link to the Creative Commons license, and indicate if changes were made.

\section{REFERENCES}

1. Adegbidi H, Atadokpede F, do Ango-Padonou F, Yedomon $H$. Keloid acne of the neck: epidemiological studies over 10 years. Int J Dermatol. 2005;44(Suppl 1):49-50.

2. Dunwell P, Rose A. Study of the skin disease spectrum occurring in an Afro-Caribbean population. Int J Dermatol. 2003;42(4):287-9.

3. George AO, Akanji AO, Nduka EU, Olasode JB, Odusan O. Clinical, biochemical and morphologic features of acne keloidalis in a black population. Int J Dermatol. 1993;32(10):714-6.

4. Glenn MJ, Bennett RG, Kelly AP. Acne keloidalis nuchae: treatment with excision and second-intention healing. J Am Acad Dermatol. 1995;33(2 Pt 1):243-6.

5. Salami T, Omeife H, Samuel S. Prevalence of acne keloidalis nuchae in Nigerians. Int J Dermatol. 2007;46(5):482-4.

6. Kelly AP. Pseudofolliculitis barbae and acne keloidalis nuchae. Dermatol Clin. 2003;21(4):645-53.

7. Dinehart SM, Herzberg AJ, Kerns BJ, Pollack SV. Acne keloidalis: a review. J Dermatol Surg Oncol. 1989;15(6):642-7.

8. Halder RM. Hair and scalp disorders in blacks. Cutis. 1983;32(4):378-80.

9. Kenney JAJ. Dermatoses: common in blacks. Postgrad Med. 1977;61(6):122-7.

10. Smith JD, Odom RB. Pseudofolliculitis capitis. Arch Dermatol. 1977;113(3):328-9.
11. Herzberg AJ, Dinehart SM, Kerns BJ, Pollack SV. Acne keloidalis. Transverse microscopy, immunohistochemistry, and electron microscopy. Am J Dermatopathol. 1990;12(2):109-21.

12. Sperling LC, Homoky C, Pratt L, Sau P. Acne keloidalis is a form of primary scarring alopecia. Arch Dermatol. 2000;136(4):479-84.

13. Alexis A, Heath CR, Halder RM. Folliculitis keloidalis nuchae and pseudofolliculitis barbae: are prevention and effective treatment within reach? Dermatol Clin. 2014;32(2):183-91.

14. Goh MSY, Magee J, Chong AH. Keratosis follicularis spinulosa decalvans and acne keloidalis nuchae. Australas J Dermatol. 2005;46(4):257-60.

15. Stieler W, Senff H, Janner M. Folliculitis nuchae scleroticans-successful treatment with 13-cis-retinoic acid (isotretinoin). Hautarzt. 1988;39(11):739-42.

16. Dinehart SM, Tanner L, Mallory SB, Herzberg AJ. Acne keloidalis in women. Cutis. 1989;44(3):250-2.

17. Harris H. Acne keloidalis aggravated by football helmets. Cutis. 1992;50(2):154.

18. Janjua SA, Iftikhar N, Pastar Z, Hosler GA. Keratosis follicularis spinulosa decalvans associated with acne keloidalis nuchae and tufted hair folliculitis. Am J Clin Dermatol. 2008;9(2):137-40.

19. Bajaj V, Langtry JAA. Surgical excision of acne keloidalis nuchae with secondary intention healing. Clin Exp Dermatol. 2008;33(1):53-5.

20. Beckett N, Lawson C, Cohen G. Electrosurgical excision of acne keloidalis nuchae with secondary intention healing. J Clin Aesthet Dermatol. 2011;4(1):36-9.

21. Califano J, Miller S, Frodel J. Treatment of occipital acne keloidalis by excision followed by secondary intention healing. Arch Facial Plast Surg. 1999;1(4):308-11.

22. Etzkorn JR, Chitwood K, Cohen G. Tumor stage acne keloidalis nuchae treated with surgical excision and secondary intention healing. J Drugs Dermatol. 2012;11(4):540-1.

23. Gloster HMJ. The surgical management of extensive cases of acne keloidalis nuchae. Arch Dermatol. 2000;136(11):1376-9.

24. Pestalardo CM, Cordero AJ, Ansorena JM, Bestue M, Martinho A. Acne keloidalis nuchae. Tissue expansion treatment. Dermatol Surg. 1995;21(8):723-4. 
25. Verma SB, Wollina U. Acne keloidalis nuchae: another cutaneous symptom of metabolic syndrome, truncal obesity, and impending/overt diabetes mellitus? Am J Clin Dermatol. 2010;11(6):433-6.

26. Layton AM, Yip J, Cunliffe WJ. A comparison of intralesional triamcinolone and cryosurgery in the treatment of acne keloids. $\mathrm{Br} \mathrm{J}$ Dermatol. 1994;130(4):498-501.

27. D'Souza P, Iyer VK, Ramam M. Familial acne keloidalis. Acta dermato-venereologica Norway. 1998;78(5):382.

28. Millan-Cayetano JF, Repiso-Jimenez JB, Del Boz J, de Troya-Martin M. Refractory acne keloidalis nuchae treated with radiotherapy. Australas J Dermatol. 2015. doi:10.1111/ajd.12380.

29. Kantor GR, Ratz JL, Wheeland RG. Treatment of acne keloidalis nuchae with carbon dioxide laser. J Am Acad Dermatol. 1986;14(2 Pt 1):263-7.

30. Azurdia RM, Graham RM, Weismann K, Guerin DM, Parslew R. Acne keloidalis in caucasian patients on cyclosporin following organ transplantation. $\mathrm{Br} \mathrm{J}$ Dermatol Engl. 2000;143(2):465-7.
31. Sattler ME. Folliculitis keloidis nuchae. WMJ. 2001;100(1):37-8.

32. Shah GK. Efficacy of diode laser for treating acne keloidalis nuchae. Indian J Dermatol Venereol Leprol. 2005;71(1):31-4.

33. Dragoni F, Bassi A, Cannarozzo G, Bonan P, Moretti $S$, Campolmi P. Successful treatment of acne keloidalis nuchae resistant to conventional therapy with 1064-nm ND:YAG laser. G Ital Dermatol Venereol. 2013. p. 231-232.

34. Esmat SM, Hay RMA, Zeid OMA, Hosni HN. The efficacy of laser-assisted hair removal in the treatment of acne keloidalis nuchae; a pilot study. Eur J Dermatol. 2012;22(5):645-50.

35. Okoye GA, Rainer BM, Leung SG, Suh HS, Kim JH, Nelson AM, et al. Improving acne keloidalis nuchae with targeted ultraviolet B treatment: a prospective, randomized, split-scalp comparison study. $\mathrm{Br} \mathrm{J}$ Dermatol. 2014;171(5):1156-63.

36. Bernárdez C, Molina-Ruiz AM, Requena L. Histologic features of alopecias: part II: scarring alopecias. Actas Dermosifiliogr. 2015;106(4): 260-70. 